\title{
Impact of Physical Activity and Type of Cooking Oil Amongst Diabetes With Co-existing Hypertension Patients on Length of Stay and Cost: General Linear Model
}

Amit Sharma ( $\nabla$ choice.amit@gmail.com )

Indo Soviet Friendship College of Pharmacy https://orcid.org/0000-0001-5037-1043

Ashish Baldi

Maharaja Ranjit Singh Punjab Technical University

Dinesh Kumar Sharma

Roorkee College of Pharmacy

Research

Keywords: General Linear Model, Physical Activity, Length of Stay, Cost of Treatment, Diabetes, Hypertension

Posted Date: November 24th, 2020

DOl: https://doi.org/10.21203/rs.3.rs-112180/v1

License: (c) (1) This work is licensed under a Creative Commons Attribution 4.0 International License.

Read Full License 


\section{Abstract}

Background: Diabetes mellitus with co-existing hypertension contributes to increased morbidity and mortality. The study aimed to investigate the impact of the patients' physical activity status and the type of cooking oil consumed by patients in their daily routine on glycemic profile, lipid profile, the hypertensive profile of the patients, and the length of stay and overall cost of the treatment.

Methods: A prospective observational study. All the patients who referred to the medicine department of the three different hospitals located in Moga, City Punjab and those who were hospitalized due to diabetes mellitus (type-I and type-II) with co-existing hypertension were asked to participate in the study.

Results: The patients' mean age was found to be $M=53.85, S D=11.54$ years. Out of 1914 patients, 914 were male (47.8\%); it was observed that the majority of the patients $525(27.43 \%)$ in North India using butter or ghee- clarified butter as edible oil, followed by mustard oil $517(27.01 \%)$ patients. About 345 $(18.03 \%)$ of the patients consume soybean oil, whereas $226(11.81 \%)$ of the patients like sunflower oil.

Discussion: This study explored that cooking oil and physical activity are associated with length of stay in days \& overall cost of the treatment, respectively. Our study results revealed that the type of oil compared with the treatment's overall cost was significant for olive oil, soybean oil, and groundnut oil.

Conclusion: The study revealed that moderate and low physical activity increases the length of stay compared to high physical activity. The consumption of olive oil as a regular food habit in daily routine decreases patients' length of stay with diabetes with coexisting hypertension when doing high physical activity but increases the overall cost of treatment.

\section{Impact Of Findings On Practice Statements}

- The present study revealed that physical activity as well as the cooking oil used in daily routine as food habit correlates length of stay and cost of treatment.

- Female patients suffering from D.M. (type-I and type-II) with co-existing hypertension had a lower mean length of stay and cost of treatment than male patients.

- In North India, majority of D.M. (type-I and type-II) with co-existing hypertension patients consume butter, ghee- clarified butter as compared to other oils which increase the cost and LOS of treatment and least chooses rice bran oil.

- Olive oil and mustard oil as a regular food habit lowers the length of stay, whereas increases the overall cost of treatment compared to rice bran oil.

\section{Background}

Diabetes mellitus (D.M.) with co-existing hypertension (HTN) contributes to increased morbidity and mortality ${ }^{1}$. The estimates reported by Domeikiene A et al. (2014) that by 2030 the number of people with 
diabetes will have risen to 552 million². The study aimed to investigate the impact of the patients' physical activity status and the type of cooking oil consumed by patients in their daily routine on glycemic profile, lipid profile, the hypertensive profile of the patients, and the length of stay and overall cost of the treatment. The study also aimed to investigate and compare the prevalence of diabetes with co-existing hypertension among men and women in Moga, a city located in Punjab state of India consuming different types of oils and doing different kinds of physical activity.

Multiple studies from western countries suggest that type of oil used by the patients in their regular diet and physical activity has a protective role against the development of D.M. and HTN. The Chinese study conducted by Yuzo S et al. (2003) elaborated in detail about physical exercise in type-2 diabetes mellitus. The results of various follow-up studies have revealed that physical activity is not only useful in preventing type-2 diabetes mellitus and improving disease status ${ }^{3}$. The patients suffering from diabetes mellitus with co-existing hypertension, the risk of death from vascular causes is 2.32 times higher than in persons without diabetes, and diabetes was once considered a coronary heart disease (CHD) risk equivalent ${ }^{4}$.

In particular, no study to our knowledge has been conducted by taking these variables for the North region of India, especially Punjab. The population staying in Punjab suffers more from D.M. and HTN than other states of India 5.

\section{Objectives}

This study objective is to provide up-to-date information regarding the physical activity and type of cooking oil consumed by patients in their daily routine and their impact on glycemic profile, lipid profile, the hypertensive profile of the patients, and the length of stay and cost. Therefore, the present study was planned to increase awareness and contribute to the length of stay and treatment cost for diabetes patients with co-existing hypertension. The primary risk factor for cardiovascular disease in diabetes mellitus is dyslipidemia ${ }^{6}$. Therefore, the lipid profile parameters, along with the glycaemic and hypertensive profile of the patients, were also studied. It was also observed from literature and as per physical activity guidelines for Americans for adults that substantial health benefits can be obtained by doing (30 minutes to 2 hours) a week of moderate-intensity physical activity or ( 1 hour and 15 minutes) a week of vigorous-intensity physical activity. In contrast, aerobic exercise should be spread throughout the week $^{7}$. Therefore, we analyzed the type of oil used by the patients in their regular diet and status of physical activity and investigated their impact on glycemic profile, lipid profile, the hypertensive profile of the patients, length of stay, and overall cost of the treatment.

\section{Setting}

In this observational study, all the patients referred to the medicine department of the three different hospitals of Moga, city located in Punjab state of India ${ }^{8,9}$ were enrolled in the study. The patients 
hospitalized due to diabetes mellitus (type-I and type-II) with co-existing hypertension from April 2017 to August 2020 were asked to participate in the study.

\section{Methods}

The present study is part of the ongoing research entitled "Drug utilization study of diabetes and hypertension at tertiary care hospital." The population size of the Moga city was found N= 2.98 lakhs $^{8}$. The sample size is calculated with the 'Epi Info' software ${ }^{10,11}$. A total of 2622 patients suffering from diabetes mellitus (D.M.) and hypertension (HTN) were screened during the study period. Out of the 2622 patients, 1914 patients were enrolled in the statistical analysis. A total of 708 patients were excluded while analyzing data because of missing value; some patients were lost during the follow-up. Thus, a total sum of 1914 patients were included for final analysis. Patients diagnosed with diabetes mellitus and hypertension with or without complications admitted to (IPD) in-patient department of the hospital. The study's inclusion criteria include patients visiting the hospital for follow-up, both genders with age $>18$ years, and diabetes with co-existing hypertension. The exclusion criteria include that patients were not willing to participate in the study.

Institutional Ethics Committee (IEC-ISFCP, Moga) ISF College of Pharmacy, Moga, Punjab approved the study (Ref. No. ECR/296/Indt/PB/2017/ISFCP/136). The confidence interval of the study is chosen as $97 \%{ }^{12}$. All statistical tests were carried out at the two-sided $3 \%$ significance level by statistical analysis software SPSS ver. 25. The study data collection form includes a questionnaire containing 105 variables. The lab investigations like blood pressure (B.P.) systolic of the patient on admission, B.P. diastolic of the patient admission, fasting blood sugar of the patient at admission, the random blood sugar of the patient at admission, $\mathrm{HbA}_{1} \mathrm{c}$ measurement of the patient, $\mathrm{HDL}$ in $\mathrm{mg} / \mathrm{dL}$ of the patient, $\mathrm{LDL}$ in $\mathrm{mg} / \mathrm{dL}$ of the patient, triglyceride level in $\mathrm{mg} / \mathrm{dL}$ of the patient, VLDL levels in $\mathrm{mg} / \mathrm{dL}$ of the patient, creatinine levels in $\mathrm{mg} / \mathrm{dL}$, were recorded during the study. Pharmacoeconomic parameters like cost of drug, direct and nondirect cost of the treatment were also recorded during the study and the length of stay in days. A predeveloped and validated tool (DCF) data collection form and patients' informed consent (PIC) were used to collect patient data. All study costs were recorded in INR, and pharmacoeconomic variables were converted to USD (INR: 73.35= 1 USD).

\section{Results}

The mean age of the patients suffering from diabetes mellitus (type-I and type-II) with co-existing hypertension $(\mu)$ and standard deviation (S.D.) was found to be $(M=53.85, S D=11.54$ ) years. The normality test was performed, which was found normally distributed Kolmogorov-Smirnov and ShapiroWilk ( $p=0.36$ and 0.223$)$, respectively ${ }^{13-15}$. Out of 1914 patients, 914 were male $(47.8 \%)$, followed by female 1000 (53.65\%).

The study's independent variable was taken as a cooking oil and physical activity status of the patients, whereas the length of stay and overall cost of the treatment was taken as a dependent variable for the 
study. During the investigation, it was found that nine different types of cooking oil were used by the patients suffering from D.M. (type-I and type-II) with co-existing hypertension in their daily routine as food habits as soybean oil, corn oil, mustard oil, olive oil, coconut oil, butter, ghee- clarified butter, groundnut oil, sunflower oil, and rice bran oil. The descriptive statistics of the patients' oil used in diet and physical activity status are represented in Figure 1 and Table 1. The patients use the cooking oil in their daily routine as food habits are coded as 0 to 9 . The three different physical categories were recorded during the study period as 0-low, 1-moderate, 2-high physical activity. The data shows out of 1914 patients enrolled in the study, soybean oil was used as cooking oil by 345 patients, followed by butter or gheeclarified butter by 525 patients, mustard oil 517 patients, corn oil 32 patients, olive oil 147 patients, coconut oil 46 patients, groundnut oil 48 patients, sunflower oil 226 patients and rice bran oil by 28 patients.

The descriptive statistics of the variable physical activity status of the patients were also recorded. Out of 1914 patients enrolled in the study, 729 patients were doing low physical activity daily, followed by 969 patients doing moderate physical activity, whereas 216 patients were doing high physical activity daily as their daily routine. Low physical activity is represented as 15-30 minutes in a day; moderate physical activity is described as 30 minutes to 1 hour in a day; high physical activity is represented as 1-2-hour in a day, including yoga (breathing exercise), aerobics, and morning and evening walk.

The descriptive statistics of type of cooking oil used by patients in their daily routine showed that most of the patients $525(27.43 \%)$ in North India use butter or ghee-clarified butter as edible oil, followed by mustard oil $517(27.01 \%)$ patients. About $345(18.03 \%)$ of the patients consume soybean oil, whereas $226(11.81 \%)$ of the patients like

sunflower oil. It was also observed that only $32(1.67 \%)$ patients are using corn oil as an edible oil in their food. Whereas olive oil was used by 147 (7.68 \%) of the patients. The coconut oil, which is most common in South India, was used by 46 (2.40\%), groundnut oil 48 (2.51\%), and rice bran oil 28 (1.46\%). The type of cooking oil used by D.M. and hypertensive patients is represented in Table 1. Figure 1 Simple bar chart represent means of the length of stay in days by type of cooking oil used by patients

On examination of the physical activity of the patients, it was seen that majority of the patients are doing moderate physical activity 969 (50.63\%) as compared to low physical activity 729 (38.09\%) followed by high physical activity 216 (11.29\%). Similar results were obtained in a study conducted by Fock K. et al. (2013) ${ }^{16}$

The mean length of stay (days) was found to be $M=6.43, S D=2.31$ days. Independent- $T$ test was performed to determine the mean length of stay (days) between male and female patients. The results of the test were found significant. This study confirms that the mean length of stay (days) of female patients suffering from D.M. (type-I and type-II) with co-existing hypertension had statistically significantly lower mean length of stay (days) $(M=5.50, S D=0.38)$ as compared to male patients $(M=$ 
$6.45, S D=0.52), t(1912)=2.428, p=0.020$. The mean difference of 0.95 days was observed. Figure 2 represents the difference in mean length of stay in days by gender of the patient.

The descriptive statistics of laboratory investigations like the patients' lipid profile, the patients' glycemic profile, and the patients' hypertensive profile were also studied during the study period. The results of lab investigations revealed that the mean cholesterol level of the patients $(M=251.86, S D=30.75) \mathrm{mg} / \mathrm{dL}$, whereas the mean high-density lipoproteins $(H D L)$ found to be $(M=31.11, S D=8.89) \mathrm{mg} / \mathrm{dL}$, low-density lipoproteins $(L D L)$ found to be $(M=176.27, S D=25.36) \mathrm{mg} / \mathrm{dL}$, the mean level of triglyceride was found to be $(M=219.55, S D=44.82) \mathrm{mg} / \mathrm{dL}$, and mean of very-low-density lipoproteins ( $V L D L)(M=42.43, S D=5.26)$ $\mathrm{mg} / \mathrm{dL}$.

On the evaluation of the blood glucose profile of the patients, it was observed that mean fasting blood sugar (FBS) $(M=272.9 \mathrm{SD}=12.15) \mathrm{mg} / \mathrm{dL}$ as compared to another study results $181.57 \mathrm{mg} / \mathrm{dL}$ conducted by Shantakumari $\mathrm{N}$ et al. $(2013)^{6}$, mean random blood sugar (RBS) was found to be $(\mathrm{M}=315.9$, $\mathrm{SD}=14.13) \mathrm{mg} / \mathrm{dL}$, and mean $\mathrm{HbA1} \mathrm{c}$ measurement $(M=7.91, \mathrm{SD}=1.01) \%$. A paired sample t-test was conducted to compare FBS and RBS level in $\mathrm{mg} / \mathrm{dL}$ of the patients during admission to the hospital with FBS and RBS level in $\mathrm{mg} / \mathrm{dL}$ during discharge. The mean FBS during discharge from the hospital was found to be $137.29 \mathrm{mg} / \mathrm{dL}$, whereas the mean RBS during discharge was found to be $186.93 \mathrm{mg} / \mathrm{dL}$. The mean difference was found significant (FBS: $p=0.001, R B S: p=0.001$ ). The mean difference between FBS during admission and discharge was 135.61 (6.08) $\mathrm{mg} / \mathrm{dL}$, whereas the mean difference between RBS during admission in hospital and discharge from hospital was 128.97 (6.96) mg/dL. Table 5 represents the details of the blood glucose profile, hypertensive profile, and lipid profile of the patients with oil during admission. The minimum FBS and RBS were found in the case of olive oil (FBS: $M=232.5$, RBS: $M=270.1) \mathrm{mg} / \mathrm{dL}$. At the same time, the minimum SBP and BPD were also found in the case of olive oil (BPS: $M=170, B P D: M=90) \mathrm{mmHg}$. The highest FBS was observed in rice bran oil (FBS: $M=296.2$ $\mathrm{mg} / \mathrm{dL})$, whereas the maximum RBS was obtained in the case of soybean oil ( $M=350.1 \mathrm{mg} / \mathrm{dL})$. The maximum $\mathrm{HbA}_{1} \mathrm{C}$ is observed in groundnut oil ( $\mathrm{M}=8.6$ percent), as shown in Table 5 .

On the evaluation of the hypertensive profile of the patients, two lab parameters were evaluated. The mean systolic blood pressure (SBP) was found to be $(M=195.03, S D=10.15) \mathrm{mmHg}$, followed by a mean diastolic blood pressure $(D B P)(M=100.33, S D=8.84) \mathrm{mmHg}$, which revealed all patients suffering from HTN. The mean serum creatinine $(M=2.8, S D=0.90) \mathrm{mg} / \mathrm{dL}$ was observed.

The pharmacoeconomic parameters like the overall cost of the treatment, cost of medical supplies and equipment, cost of diagnostic tests (\$), and cost of the drug (\$) were also evaluated for the study's patients. The pharmacoeconomic parameters were chosen as per the recommendation of Richard $\mathrm{E}$ et al. (2003) for the treatment's direct and indirect cost ${ }^{17}$. On evaluating pharmacoeconomic parameters, it was observed that the overall (direct and non-direct) mean cost of the treatment was found to be $(M=309.33, S D=78.64)$ USD. The mean cost of medical supplies and equipment was found to be $(M=21.37, S D=3.77)$ USD. On evaluation, it was also found that the mean cost of diagnostic tests was found to be $(M=14.85, S D=2.63)$ USD, followed by the mean cost of the drug $(M=13.54, S D=7.0)$ USD. The 
data of pharmacoeconomic parameters, the patients' hypertensive profile, the patients' lipid profile, and the patients' glucose profile are represented in Table 1.

The General Linear Model (ANCOVA) was performed to find out the correlation of cooking oil and physical activity status of the patients with a length of stay and overall cost of the treatment for the patients suffering from D.M. (type-I and type-II) with co-existing hypertension.

Table 2 represents the type of cooking oil used by the patients as an independent variable, whereas the length of stay in days and overall cost of the treatment (USD) per day dependent variable. The descriptive statistics of the length of stay and cost of the treatment reveals that the highest cost of the treatment was observed in patients consuming olive oil 147 patients $(M=82.65, S D=48.44)$ USD followed by groundnut oil 48 patients $(M=71.51, S D=78.92)$

In correlation with physical activity status, the highest cost of the treatment was observed in patients consuming soybean oil and doing high physical activity ten patients $(M=85.60, S D=35.47)$ USD, whereas the length of the stay reduces $(M=4.80, S D=2.7)$ days.

The group-wise statistics reveal that the lowest length of stay was observed in patients consuming olive oil and doing high physical activity. For patients consuming olive oil and doing high physical activity, the length of stay in days (LOS) was found to be $130(M=3.49, S D=1.87)$ and the overall cost of treatment in USD (OCT) 130 ( $M=84.18$, SD 50.86). Patients consuming olive oil and doing moderate physical activity, LOS was found to be $7(M=4.0, S D=1.15)$, and OCT was found to be $7(M=69.21, S D=25.09)$. Patients consuming olive oil and doing low physical activity, LOS was found to be $10(M=4.90, S D=1.59)$, and OCT was found to be $10(M=72.18, S D=16.75)$. A maximum of 525 patients was consuming butter, gheeclarified butter. The mean LOS was found to be $(M=7.80, S D=1.77)$, whereas the mean OCT was found to be $(M=42.67, S D=11.83)$. It was also revealed that only 28 patients consumed rice bran oil, and maximum LOS was found to be $(M=9.61, S D=2.39)$, whereas the OCT was found to be $(M=36.52, S D=3.87)$. The length of stay in days and the overall cost of the treatment per day is represented in Table 2.

The General Linear Model (GLM) (ANCOVA) analysis of covariance was performed to find out the impact and relationship of the cooking oil used by the patients and physical activity as independent variable whereas the length of stay in days and overall cost of the treatment (USD) per day dependent variable. Levene's test was found $>0.03$, which shows equal variances. The results of ANCOVA show that cooking oil and physical activity are associated with length of stay in days \& overall cost of the treatment per day ( $P=0.001$ and $P=0.001$ ), respectively. The results of dependent variable length of stay was found significant $(\mathrm{F}(8,1903)=8.25, P<0.001)$, physical activity $(F(8,1903)=2.89, P<0.001)$ as shown in

\section{Table 3.}

When compared with the length of stay, all types of oil were found significant ( $p$ = value of all kinds of cooking oil was found 0.001 ) compared to physical activity when compared length of stay in days; the results were also found significant. The significant value for moderate physical activity was found to be $(p=0.030)$, whereas, for low physical activity, the significant value was found to be $(p=0.001)$, as shown in 
Table 4. The estimated marginal means of the length of stay in days with the type of cooking oil with physical activities is represented in Figure $\mathbf{3}$ whereas Figure 4 represent the estimated marginal means of the overall cost of the treatment per day in INR with the type of cooking oil with physical activities.

The results of all types of oil when compared with the overall cost of the treatment it was found that significant results were obtained for the olive oil $(p=0.001)$, corn oil $(p=0.001)$, soybean oil $(p=0.030)$, and groundnut oil ( $p=0.001)$. Simultaneously, the non-significant results were obtained in mustard oil, coconut oil, butter, ghee, and groundnut oil compared to rice bran oil. When compared the overall cost of the treatment, the type of physical activity was also found significant. The significant value for moderate physical activity was found to be $(p=.026)$, whereas low physical activity significant value was found to be (.017) compared to high physical activity, as shown in Table 4.

The parameter estimates data of the dependent variable length of stay in days revealed that moderate physical activity resulted in increased length of stay suggested by $\beta$ of 0.09 days, while low physical activity increases over $\beta$ of 0.39 days compared to high physical activity. Whereas the parameter estimates data of dependent variable overall cost of the treatment per day revealed that moderate physical activity resulted in the lower overall cost of the treatment suggested by $\beta$ of -503.8 INR (-\$6.87), while low physical activity lowers the cost over $\beta$ of -752.8 INR $(-\$ 10.26)$ compared to high physical activity.

On the evaluation of results of the cooking oil, the parameter estimates data of the dependent variable length of stay in days revealed that consumption of olive oil as a regular food habit lower the length of stay suggested by $\beta$ of -5.26 days whereas increases the overall cost of treatment as indicated by $\beta$ of 2714.6 INR (\$37.01). The results of mustard oil as a regular food habit lower the length of stay shown by $\beta$ of -4.17 days, whereas increases the overall cost of treatment as suggested by $\beta$ of 1732.5 INR (\$23.62) as compared to rice bran oil.

The study also highlighted that reason for low physical activity and exercise was found to be laziness to wake up early in the morning for a morning walk in 426 (58.43\%), Lack of power, energy, or physical stamina 222 (30.45\%), and personal health 81 (11.11\%).

\section{Main outcome measure:}

This study reveals that the mean length of stay (days) of the patients suffering from D.M. and hypertensive patients is 6 to 7 days, as compared with 5.98 days reported by Rajhans A et al. $(2019)^{18}$. Our study confirms that female patients suffering from D.M. (type-I and type-II) with co-existing hypertension had a statistically significantly lower mean length of stay than male patients. At the same time, opposite results were observed in male (56.7 \%) patients in the study reported by Hiroki F et al. $(2019)^{19}$.

In this study, it was observed that the majority of the patients in North India using butter or ghee- clarified butter as edible oil, followed by mustard oil. The study conducted by Kumar A et al. (2018) discussed in 
detail the importance and health benefits of using ghee (trans-fatty acids) as cooking oil ${ }^{20}$. Kumar A et al. (2018) also reported that North Indians consume ghee more than other oils in their daily routine 20 . The least used cooking oil used by patients daily as food habit was groundnut oil and rice bran oil. Manchanda S et al. (2016) reported a similar view in his study ${ }^{21}$.

This study reveals that the highest cost of the treatment was observed in patients consuming olive oil 82.65 USD, followed by 71.51 USD groundnut oil. In correlation with physical activity status, the highest cost of the treatment was observed in patients consuming soybean oil and doing high physical activity $M=85.60$ USD, whereas the length of the stay reduces 2.7 days.

This study reveals that the lowest length of stay was observed in patients consuming olive oil, whereas doing high physical activity. Patients consuming olive oil and doing high physical activity, length of stay in days (LOS) was found to be 3.49 days, and the overall cost of treatment in USD 84.18. The cost of treatment is compared with other studies held in different years; the survey reported by Wolfgang $\mathrm{R}$ et al. (2007) have reported the cost of therapy 86.7 USD in 1994, 172.1 USD in $2004{ }^{22}$. Patients consuming olive oil and doing moderate physical activity LOS was found 4.0 days, and OCT was found 69.21 USD. Patients consuming olive oil and doing low physical activity LOS was found 4.90 days, and OCT was found 72.18 USD. It was also revealed that the maximum mean length of stay was found for the patients consuming rice bran oil 9.61 days, with the overall cost of treatment 36.52 USD. The treatment's direct cost was 188.5 USD, whereas the in-direct cost of treatment 39.1 USD. The overall cost of treatment was found to be 295.6 USD. At the same time, the overall cost of therapy per day was found to be 46.1 USD.

Our study results show that cooking oil and physical activity are associated with length of stay in days \& overall treatment costs. The results of the dependent variable length of stay and physical activity were found significant. The results of all types of oil compared with the length of stay showed substantial results, whereas physical activity when the compared length of stay in days was also significant. Our study results revealed that the type of oil compared with the treatment's overall cost was highly significant for olive oil, soybean oil, and groundnut oil. Simultaneously, the non-significant results were obtained in mustard oil, coconut oil, butter, ghee, and groundnut oil compared to rice bran oil. Previous studies suggest that Indian cooking conditions subject oil to very high temperatures, like in deep frying, at 170 degrees Celsius ${ }^{23}$. Katragadda $\mathrm{H}$ et al. (2010) reported that certain oils, especially soyabean oil, mustard oil, and ghee, can degrade quickly to toxic components like free radical and transfat, melondialdehyde (MDA), which are potentially mutagenic and atherogenic ${ }^{24}$. The minimum FBS and RBS were found in olive oil simultaneously. The minimum SBP and BPD were also found in the case of olive oil. The highest FBS was observed in rice bran oil, whereas the maximum RBS was obtained in soybean oil. The maximum $\mathrm{HbA}_{1} \mathrm{C}$ is observed in groundnut oil followed by butter, ghee- clarified butter. The minimum $\mathrm{HbA}_{1} \mathrm{C}$ is observed in olive oil (6.7\%). The maximum level of $\mathrm{HDL}$ is observed in olive oil $(\mathrm{M}=$ $36.2 \mathrm{mg} / \mathrm{dL})$.

Compared with the overall cost of the treatment, the type of physical activity was also found significant. The results of moderate physical activity were found significant as compared to high physical activity. It 
was also revealed that moderate physical activity resulted in an increased length of stay by 0.09 days, while low physical activity increases 0.39 days compared to high physical activity. Simultaneously, the overall cost of the treatment per day revealed that moderate physical activity lowers the overall cost of the treatment by -503.8 INR (-\$6.87), while low physical activity reduces the cost -752.8 INR $(-\$ 10.26)$ compared to high physical activity. Our study results revealed that olive oil consumption as a regular food habit lowers the length of stay by -5.26 days, whereas it increases the overall cost of treatment by 2714.6 INR (\$37.01). The mustard oil as a regular food habit lowers the length of stay -4.17 days, whereas it increases the overall cost of treatment by 1732.5 INR (\$23.62) compared to rice bran oil. The oils are a specific diet component that provides essential fatty acids and facilitates various other vitally crucial nutrients for normal physiological functions ${ }^{25}$. The study also highlighted that reason for low physical activity and exercise to be laziness to wake up early in the morning for a morning walk in most of the patients as the same reported in other studies ${ }^{26}$. Lack of power, energy, or physical stamina and personal health issue were barriers identified in this study and others for low physical activity ${ }^{26}$.

\section{Conclusion}

Our study concludes that moderate and low physical activity increases the length of stay compared to high physical activity. This study is the first of its kind in North India and is important for many reasons. First, the consumption of olive oil as a regular food habit in daily routine decreases the length of stay of patients who have diabetes with coexisting hypertension when doing the high physical activity but increases the overall cost of treatment. Mustard oil as a regular food habit lowers the length of stay, whereas it increases the overall cost of treatment compared to rice bran oil. The study also concludes that female patients suffering from D.M. (type-I and type-II) with co-existing hypertension had a lower mean length of stay than male patients. In North India, the maximum patients suffering from D.M. (type-I and type-II) with co-existing hypertension consume butter, ghee- clarified butter. The study also revealed that the North Indian population least chooses rice bran oil. Secondly, cooking oil and physical activity play an essential role in the etiology of most chronic disorders like diabetes and contribute to the effective prevention of other diseases ${ }^{26}$. In conclusion, patients should advise adopting an effective and healthy lifestyle diet, together with physical activity, are the cornerstone in preventing diabetes with coexisting hypertension.

\section{Abbreviations}

INR: Indian Rupees, USD: United States Dollar, OCT: Overall cost of treatment, LOS: Length of stay, GLM: General linear model, D.M.: Diabetes mellitus, HTN: Hypertension. HDL: High-density lipoproteins, LDL: Low-density lipoproteins, VLDL: Very-low-density lipoproteins, SBP: Systolic blood pressure, DBP: Diastolic blood pressure, FBS: Fasting blood sugar, RBS: Random blood sugar.

\section{Declarations}


Ethics approval and consent to participate: Informed consent was obtained from all the patients. All procedures performed in studies involving human participants followed the institutional and national research committee's ethical standards and the 1964 Helsinki Declaration and its later amendments or comparable ethical standards. The present study was approved by IEC of ISF College of Pharmacy, Moga, Punjab (Ref. No. ECR/296/Indt/PB/2017/ISFCP/136).

Consent for publication: The patient informed consent (PIC) was taken from all the patients enrolled in study.

Availability of data and materials: The current research work entitled "Drug utilization study on diabetes mellitus and hypertension at tertiary care hospital" is ongoing study having multiple objectives. The data of the same is not deposited in any database. The data will be made available on reasonable request from corresponding author via e-mail: amit@gmail.com.

Competing interests: All the authors have declared that no competing interests exist.

Funding: There are no funding sources for this report.

Authors' contributions: AS: Collected data in ongoing study and writing the manuscript, data analysis, AB: Major contributor in writing, drafting the manuscript., DKS: Major contributor in writing and drafting the manuscript, all authors read and approved the final manuscript.

Acknowledgements: We thank the patient for sharing their details and thank ISF College of Pharmacy, Moga, Punjab, and SD Thappar, Moga, Garg Hospital, Moga Medicity Punjab Hospital staff for continuous support provided.

\section{References}

1. Alavi N, Alami L, Taefi S, Gharabagh G. Factor analysis of self-treatment in diabetes mellitus: A crosssectional study. BMC Public Health 2011; 11: 761.

2. Aguirre F, Alwan A, Bowers R, Dain K, Dahlquist G, Dodd S et al. IDF Diabetes Atlas. Int. Diabetes Fed. Diabetes Atlas - sixth Ed. 2013; : 1-144.

3. Matsuzawa Y. The role of fat topology in the risk of disease. Int J Obes 2008; 32: S83-S92.

4. Tonding SF, Silva FM, Antonio JP, Azevedo MJ, Canani LHS, Almeida JC. Adiposity markers and risk of coronary heart disease in patients with type 2 diabetes mellitus. Nutr J 2014; 13: 1-7.

5. Mohan B, Sharma S, Sharma S, Kaushal D, Singh B, Takkar S et al. Assessment of knowledge about healthy heart habits in urban and rural population of Punjab after SMS campaign-A cross-sectional study. Indian Heart J 2017; 69: 480-484.

6. Shantakumari N, Sequeira S, El Deeb R. Effects of a yoga intervention on lipid profiles of diabetes patients with dyslipidemia. Indian Heart J 2013; 65: 127-131. 
7. Azar AM, Vaux-Bjerke A, Fulton JE, Pfohl SY, D R, L K et al. Physical activity guidelines for Americans. In: U.S. Department of Health and Human Services. 2018, pp 1-113.

8. Directorate of Census Operations P. District census handbook, Moga. 2011.

9. Sharma ML. Punjab-at-a-glance (district wise) 2011. 2012http://www.pbplanning.gov.in/pdf/PunjabGlance2011CompleteVD Graphs.pdf.

10. CDC. Epi Info 7 - User Guide. 2016http://www.cdc.gov/epiinfo/pdfs/UserGuide/El7Full.pdf.

11. Clark V. Sample size determination. Plast Reconstr Surg 1991; 87: 569-573.

12. Sharma A, Neha J, Ashish B, DK S. Socio-Demographic Characteristics and Drug Related Problems of Patients Presenting to the Emergency Department: General Linear Model and Factorial Analysis. $J$ Pharm Care Heal Syst 2018; 05. doi:10.4172/2376-0419.1000198.

13. Kafadar K. Testing for Normality. J Am Stat Assoc 2003; 98: 765-765.

14. Ghasemi A, ZahediasI S. Normality tests for statistical analysis: A guide for non-statisticians. Int $J$ Endocrinol Metab 2012; 10: 486-489.

15. Altman DG, Gore SM, Gardner MJ, Pocock SM. Statistical guidelines for contribution to medical journals. BMJ 1983; 1: 1489-1493.

16. Fock KM, Khoo J. Diet and exercise in management of obesity and overweight. J Gastroenterol Hepatol 2013; 28: 59-63.

17. Ernst R. Indirect costs and cost-effectiveness analysis. Value Hea/ 2006; 9: 253-261.

18. A RP, Y KP, S KD, A JS, Gouri R, Sonal U et al. Effect of diabetes on severity of illness, length of hospital stay and mortality among patients brought by EMS. Int J Med Public Heal 2017; 7: 156161.

19. Fujii H, Iwase M, Ohkuma T, Ogata-Kaizu S, Ide H, Kikuchi Y et al. Impact of dietary fiber intake on glycemic control, cardiovascular risk factors and chronic kidney disease in Japanese patients with type 2 diabetes mellitus: The Fukuoka Diabetes Registry. Nutr J 2013; 12: 1-8.

20. Kumar A, Tripathi S, Hans N, Pattnaik H SN. Ghee: Its properties, importance and health genefits. Lipid Universe 2018; 6: 6-14.

21. Manchanda SC, Passi SJ. Selecting healthy edible oil in the Indian context. Indian Heart J 2016; 68: 447-449.

22. Rathmann W, Haastert B, Icks A, Giani G. Trends in outpatient prescription drug costs in diabetic patients in Germany, 1994-2004. Diabetes Care 2007; 30: 848-853.

23. Wang KS, Liu Y, Xie X, Gong S, Xu C, Sha Z. Principal component regression analysis of nutrition factors and physical activities with diabetes. J Biom Biostat 2017; 08: 4-10.

24. Katragadda HR, Fullana A, Sidhu S, Carbonell-Barrachina ÁA. Emissions of volatile aldehydes from heated cooking oils. Food Chem 2010; 120: 59-65.

25. Dineshkumar B, Mukherjee S, Pradhan R, Mitra A, Chakraborty C. Effects of edible oils in type 2 diabetes mellitus. J Clin Diagnostic Res 2009; 3: 1389-1394. 
26. Ghimire S. Barriers to Diet and Exercise among Nepalese Type 2 Diabetic Patients. Int Sch Res Not 2017; 2017: 1-9.

\section{Tables}

Table 1 Descriptive statistics of the variable included in study 


\begin{tabular}{|c|c|c|}
\hline Variable & Mean & Std. Deviation \\
\hline Age (mean) (years) & 53.85 & 11.54 \\
\hline Gender (\%) & 914 & $47.8^{*}$ \\
\hline Length of stay (days) & 6.43 & 2.31 \\
\hline Overall cost of the treatment $(\$)$ & $309.33^{a}$ & $78.64^{a}$ \\
\hline Cost of medical supplies and equipment's (\$) & $21.37^{a}$ & $3.77^{a}$ \\
\hline Cost of diagnostic tests (\$) & $14.85^{a}$ & $2.63^{a}$ \\
\hline Cost of the drug $((\$)$ & $13.54^{a}$ & $7.00^{a}$ \\
\hline Cholesterol level of the patients $(\mathrm{mg} / \mathrm{dL})$ & 251.86 & 30.75 \\
\hline $\mathrm{HDL}(\mathrm{mg} / \mathrm{dL})$ & 31.11 & 8.89 \\
\hline $\mathrm{LDL}(\mathrm{mg} / \mathrm{dL})$ & 176.27 & 25.36 \\
\hline Triglyceride (mg/dL) & 219.55 & 44.82 \\
\hline $\operatorname{VLDL}(\mathrm{mg} / \mathrm{dL})$ & 42.43 & 5.26 \\
\hline Creatinine (mg/dL) & 2.79 & 0.90 \\
\hline BP Systolic (mmHg) & 195.03 & 10.15 \\
\hline BP Diastolic (mmHg) & 100.33 & 8.84 \\
\hline Fasting blood sugar (mg/dL) & 272.89 & 12.15 \\
\hline Random blood sugar (mg/dL) & 315.89 & 14.13 \\
\hline $\mathrm{HbA}_{1} \mathrm{c}$ measurement $(\%)$ & $7.91^{*}$ & 1.01 \\
\hline \multicolumn{3}{|l|}{ Type of cooking oil used by patients } \\
\hline Soybean oil & $345^{\#}$ & $18.03 *$ \\
\hline Corn oil & $32 \#$ & $1.67 *$ \\
\hline Mustard oil & 517 \# & $27.01 *$ \\
\hline Olive oil & $147^{\#}$ & $7.68 *$ \\
\hline Coconut oil & $46^{\#}$ & $2.40 *$ \\
\hline Butter, Ghee- clarified butter & $525 \#$ & $27.43^{*}$ \\
\hline Groundnut oil & $48^{\#}$ & $2.51 *$ \\
\hline
\end{tabular}




\begin{tabular}{|lll|}
\hline Sunflower oil & $226^{\#}$ & $11.81^{*}$ \\
\hline Rice bran oil & $28^{\#}$ & $1.46^{*}$ \\
\hline Physical activity status & & \\
\hline Low: $15-30$ minutes/ day & $729^{\#}$ & $38.09 *$ \\
\hline Moderate: 30 minutes to 1 hour/ day & $969^{\#}$ & $50.63 *$ \\
\hline High: 1-2-hour/ day & $216^{\#}$ & $11.29 *$ \\
\hline
\end{tabular}

HDL: high-density lipoproteins, LDL: low-density lipoproteins, TG: Triglycerides, VLDL: very-low-density lipoproteins, BPS: blood pressure systolic, BPD: blood pressure diastolic, FBS: fasting bold sugar, RBG: random bold sugar, INR: Indian rupees, USȘ: United States dollar. *Percentage, ${ }^{{ }^{-}}$(USS), ${ }^{*}$ - Frequency

Table 2 Type of cooking oil: Dependent variable: Length of stay in days and overall cost of the treatment per day 


\begin{tabular}{|c|c|c|c|c|c|c|c|}
\hline \multirow{2}{*}{$\begin{array}{l}\text { Variable } \\
\text { Type of cooking oil } \\
\text { used by patients }\end{array}$} & \multirow[b]{2}{*}{$\begin{array}{l}\text { Physical } \\
\text { activity status }\end{array}$} & \multicolumn{3}{|c|}{ Length of stay in days } & \multicolumn{3}{|c|}{$\begin{array}{l}\text { Overall cost (\$) of the } \\
\text { treatment per day }\end{array}$} \\
\hline & & Mean & $\begin{array}{l}\text { Std. } \\
\text { Deviation }\end{array}$ & $\mathrm{N}$ & $\begin{array}{l}\text { Mean } \\
\$\end{array}$ & $\begin{array}{l}\text { Std. } \\
\text { Deviation }\end{array}$ & $\mathrm{N}$ \\
\hline \multirow[t]{4}{*}{ Soybean oil } & Low & 7.00 & 1.51 & 14 & 48.19 & 8.06 & 14 \\
\hline & Moderate & 6.39 & 1.87 & 321 & 53.67 & 16.79 & 321 \\
\hline & High & 4.80 & 2.70 & 10 & 85.60 & 35.47 & 10 \\
\hline & Total & 6.37 & 1.90 & 345 & 54.37 & 18.11 & 345 \\
\hline \multirow[t]{4}{*}{ Corn oil } & Low & 7.08 & 1.31 & 12 & 42.11 & 4.20 & 12 \\
\hline & Moderate & 6.65 & 1.49 & 17 & 45.99 & 6.63 & 17 \\
\hline & High & 5.67 & 2.51 & 3 & 57.26 & 27.54 & 3 \\
\hline & Total & 6.72 & 1.52 & 32 & 45.59 & 9.79 & 32 \\
\hline \multirow[t]{4}{*}{ Mustard oil } & Low & 5.00 & 1.32 & 9 & 52.97 & 11.29 & 9 \\
\hline & Moderate & 5.14 & 1.75 & 451 & 63.86 & 50.93 & 451 \\
\hline & High & 5.16 & 2.24 & 57 & 67.88 & 30.67 & 57 \\
\hline & Total & 5.14 & 1.80 & 517 & 64.12 & 48.68 & 517 \\
\hline \multirow[t]{4}{*}{ Olive oil } & Low & 4.90 & 1.59 & 10 & 72.18 & 16.75 & 10 \\
\hline & Moderate & 4.00 & 1.15 & 7 & 69.21 & 25.09 & 7 \\
\hline & High & 3.49 & 1.87 & 130 & 84.18 & 50.86 & 130 \\
\hline & Total & 3.99 & 1.82 & 147 & 82.65 & 48.44 & 147 \\
\hline \multirow[t]{3}{*}{ Coconut oil } & Low & 7.32 & 2.55 & 44 & 50.22 & 28.15 & 44 \\
\hline & Moderate & 8.00 & 0.01 & 2 & 37.70 & 0.61 & 2 \\
\hline & Total & 7.35 & 2.49 & 46 & 49.68 & 27.64 & 46 \\
\hline \multirow{4}{*}{$\begin{array}{l}\text { Butter, Ghee- clarified } \\
\text { butter }\end{array}$} & Low & 7.82 & 1.77 & 495 & 42.51 & 11.23 & 495 \\
\hline & Moderate & 7.47 & 1.89 & 19 & 46.80 & 23.90 & 19 \\
\hline & High & 7.55 & 1.03 & 11 & 43.02 & 6.90 & 11 \\
\hline & Total & 7.80 & 1.77 & 525 & 42.67 & 11.83 & 525 \\
\hline \multirow[t]{3}{*}{ Groundnut oil } & Moderate & 6.40 & 2.28 & 47 & 71.40 & 79.77 & 47 \\
\hline & High & 4.00 & & 1 & 76.45 & - & 1 \\
\hline & Total & 6.35 & 2.28 & 48 & 71.51 & 78.92 & 48 \\
\hline
\end{tabular}




\begin{tabular}{|llllllll|}
\hline Sunflower oil & Low & 7.47 & 2.62 & 118 & 45.31 & 26.69 & 118 \\
\cline { 2 - 7 } & Moderate & 7.04 & 1.76 & 104 & 49.34 & 36.91 & 104 \\
\cline { 2 - 7 } & High & 8.75 & 2.06 & 4 & 36.06 & 4.29 & 4 \\
\hline Rice bran oil & Total & 7.30 & 2.26 & 226 & 47.00 & 31.63 & 226 \\
& Low & 9.63 & 2.43 & 27 & 36.42 & 3.90 & 27 \\
\hline Moderate & 9.00 & $\cdot$ & 1 & 39.46 & - & 1 \\
\hline Total & 9.61 & 2.39 & 28 & 36.52 & 3.87 & 28 \\
\hline Low & 7.68 & 2.10 & 729 & 43.84 & 16.50 & 729 \\
\hline Moderate & 5.89 & 1.97 & 969 & 58.60 & 42.52 & 969 \\
\hline High & 4.63 & 2.23 & 216 & 76.55 & 44.85 & 216 \\
\hline Total & 6.43 & 2.30 & 1914 & 55.00 & 36.75 & 1914 \\
\hline
\end{tabular}

Table 3 Tests of between-subject's effects: Dependent variable: Overall cost of the treatment per day

\begin{tabular}{|llllll|}
\hline Source & Type III Sum of Squares & $\mathrm{df}$ & Mean Square & $\mathrm{F}$ & Sig. \\
\hline Corrected Model & $1525210956.6^{\mathrm{a}}$ & 10 & 152521095.6 & 23.45 & .001 \\
\hline Intercept & 8499816936.6 & 1 & 8499816936.6 & 1306.86 & .001 \\
\hline OIL & 429584313.0 & 8 & 53698039.1 & 8.25 & .001 \\
\hline PHYACT & 37655690.9 & 2 & 18827845.4 & 2.89 & .026 \\
\hline Error & 12377102182.5 & 1903 & 6503994.8 & & \\
\hline Total & 45058620816.4 & 1914 & & & \\
\hline Corrected Total & 13902313139.1 & 1913 & & \\
\hline a. $R$ Squared $=.110$ (Adjusted $R$ Squared $=.105)$ Cost in INR & & \\
\hline
\end{tabular}

Table 4 Parameter estimates: Dependent variable: Length of stay in days and over all cost of treatment INR (USD) 


\begin{tabular}{|c|c|c|c|c|c|c|}
\hline \multirow[t]{2}{*}{ Parameter } & \multicolumn{3}{|c|}{ Length of stay in days } & \multicolumn{3}{|c|}{$\begin{array}{l}\text { Over all cost of } \\
\text { treatment INR (USD) }\end{array}$} \\
\hline & B & $\mathrm{t}$ & Sig. & B & $t$ & Sig. \\
\hline Intercept & 9.21 & 21.4 & .001 & $3422.9(\$ 46.67)$ & 5.96 & .001 \\
\hline [OIL= Soybean oil] & -2.95 & -7.2 & .001 & $1064.3(\$ 14.51)$ & 1.95 & .030 \\
\hline [OIL= Corn oil] & -2.70 & -5.3 & .001 & $471.0(\$ 6.42)$ & .70 & .484 \\
\hline [OIL= Mustard oil] & -4.17 & -10.3 & .001 & $1732.5(\$ 23.62)$ & 3.21 & .001 \\
\hline [OIL= Olive oil] & -5.26 & -11.7 & .001 & $2714.6(\$ 37.01)$ & 4.55 & .001 \\
\hline [OIL= Coconut oil] & -2.25 & -4.9 & .001 & $963.0(\$ 13.13)$ & 1.57 & .115 \\
\hline [OIL= Butter, Ghee] & -1.79 & -4.8 & .001 & $435.1(\$ 5.93)$ & .88 & .379 \\
\hline [OIL= Groundnut oil] & -2.96 & -6.1 & .001 & $2315.3(\$ 31.57)$ & 3.58 & .001 \\
\hline [OIL= Sunflower oil] & -2.17 & -5.5 & .001 & $649.4(\$ 8.85)$ & 1.24 & .213 \\
\hline [OIL= Rice bran oil] & $0^{\mathrm{a}}$ & & . & $0^{\mathrm{a}}$ & . & . \\
\hline [PHYACT=Low] & 0.39 & 1.6 & .026 & $-752.8(-\$ 10.26)$ & -2.38 & .017 \\
\hline [PHYACT=Moderate] & 0.09 & 0.42 & .030 & $-503.8(-\$ 6.87)$ & -1.86 & .026 \\
\hline [PHYACT=High] & $0^{\mathrm{a}}$ & . & . & $0^{a}$ & . & . \\
\hline
\end{tabular}

Table 5 Blood glucose profile, hypertensive profile and lipid profile of the patients during admission with type of cooking oil 


\begin{tabular}{|lllllllll|}
\hline Type of oil & FBS & RBS & SBP & DBP & CHO & HDL & VLDL & $\mathrm{HbA}_{1} \mathrm{C}$ \\
\hline Soybean oil & $\mathrm{mg} / \mathrm{dL}$ & $\mathrm{mg} / \mathrm{dL}$ & $\mathrm{mmHg}$ & $\mathrm{mmHg}$ & $\mathrm{mg} / \mathrm{dL}$ & $\mathrm{mg} / \mathrm{dL}$ & $\mathrm{mg} / \mathrm{dL}$ & $\%$ \\
\hline Corn oil & 266.5 & 350.1 & 198 & 100 & 260.2 & 29.2 & 42.5 & 7.8 \\
\hline Mustard oil & 269.6 & 328.1 & 195 & 105 & 257.1 & 28.1 & 42.6 & 7.6 \\
\hline Olive oil & 272.25 & 322.15 & 210 & 105 & 255.3 & 26.3 & 43.2 & 7.9 \\
\hline Coconut oil & 232.5 & 270.1 & 170 & 90 & 230.2 & 36.2 & 38.2 & 6.7 \\
\hline $\begin{array}{l}\text { Butter, Ghee- } \\
\text { clarified butter }\end{array}$ & 255.5 & 318.05 & 199 & 105 & 264.2 & 32.5 & 48.6 & 8.1 \\
\hline Groundnut oil & 289.25 & 290.26 & 194 & 100 & 261.1 & 31.5 & 42.3 & 8.4 \\
\hline Sunflower oil & 292.2 & 318.12 & 201 & 100 & 248.6 & 33.2 & 40.2 & 8.2 \\
\hline Rice bran oil & 296.2 & 321.2 & 193 & 100 & 257.2 & 31.2 & 43.2 & 7.9 \\
\hline Mean & 272.9 & 315.9 & 195.0 & 100.3 & 251.8 & 31.1 & 42.4 & 7.9 \\
\hline
\end{tabular}

HDL: high-density lipoproteins, LDL: low-density lipoproteins, TG: Triglycerides, VLDL: very-low-density lipoproteins, BPS: blood pressure systolic, BPD: blood pressure diastolic, FBS: fasting bold sugar, RBG: random bold sugar

\section{Figures}




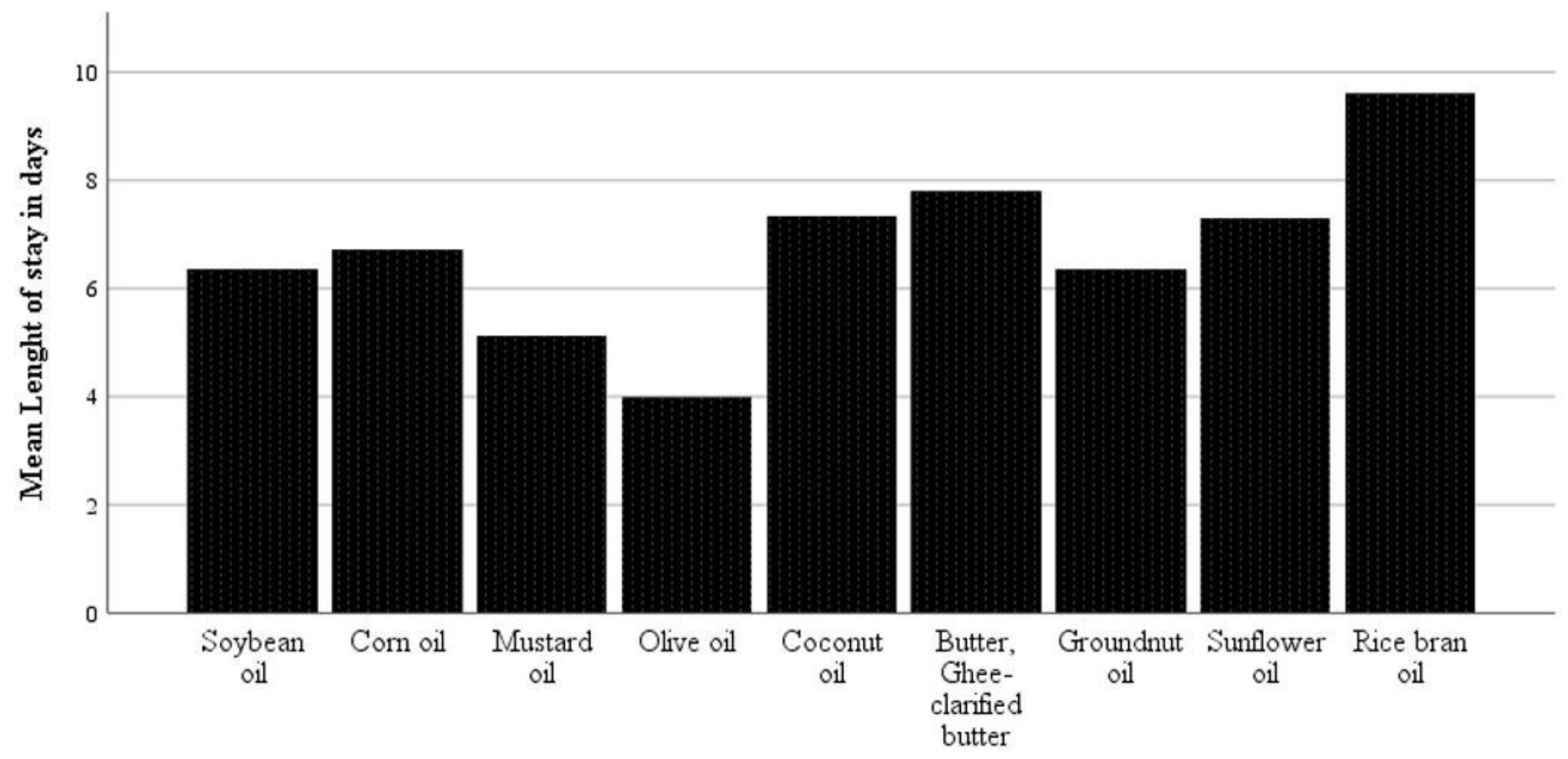

Type of cooking oil used by patients

Filtered by Gender of the patient variable

\section{Figure 1}

Simple bar means of the length of stay in days by type of cooking oil used by patients

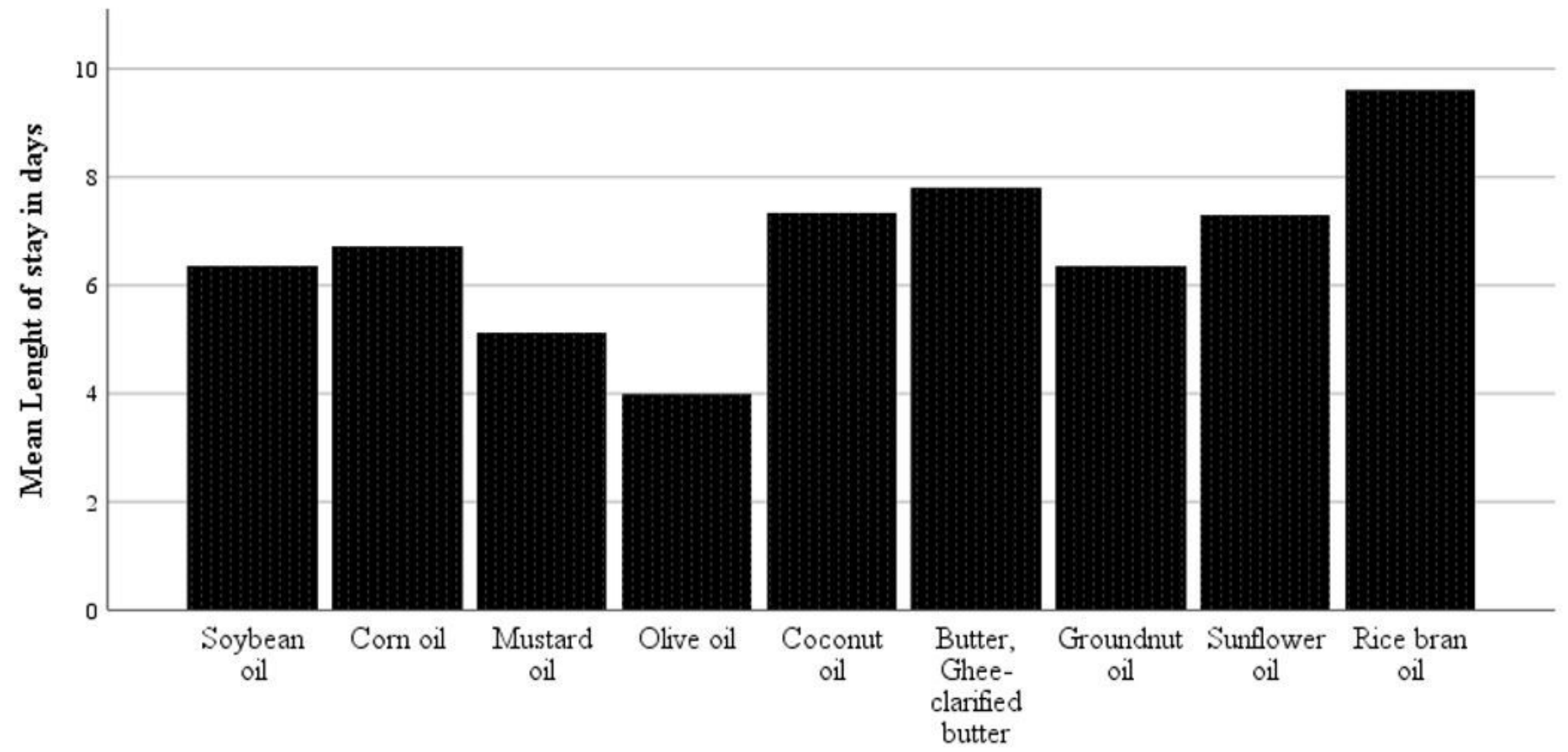

Type of cooking oil used by patients

Filtered by Gender of the patient variable 
Figure 1

Simple bar means of the length of stay in days by type of cooking oil used by patients

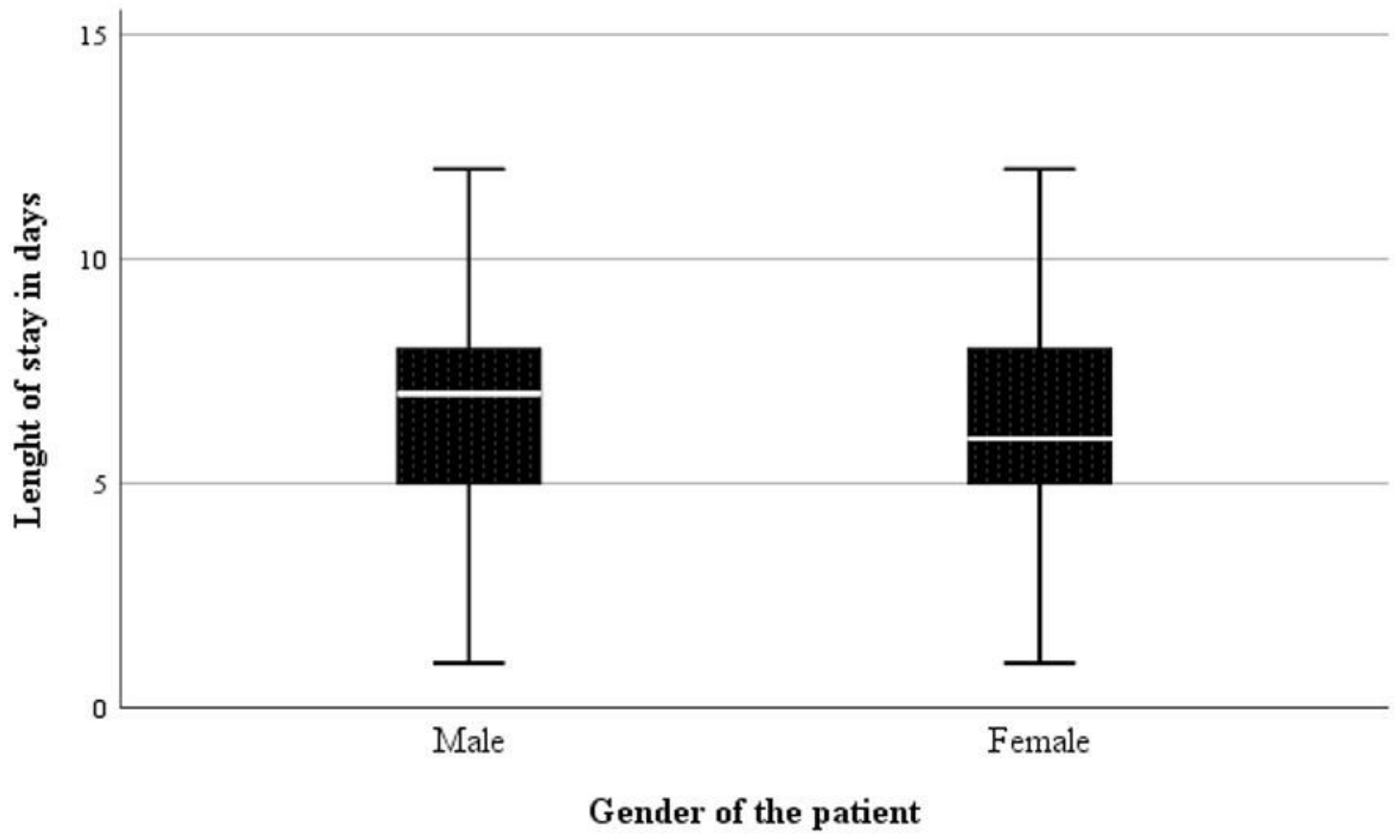

Figure 2

Simple boxplot of the length of stay in days by gender of the patient 


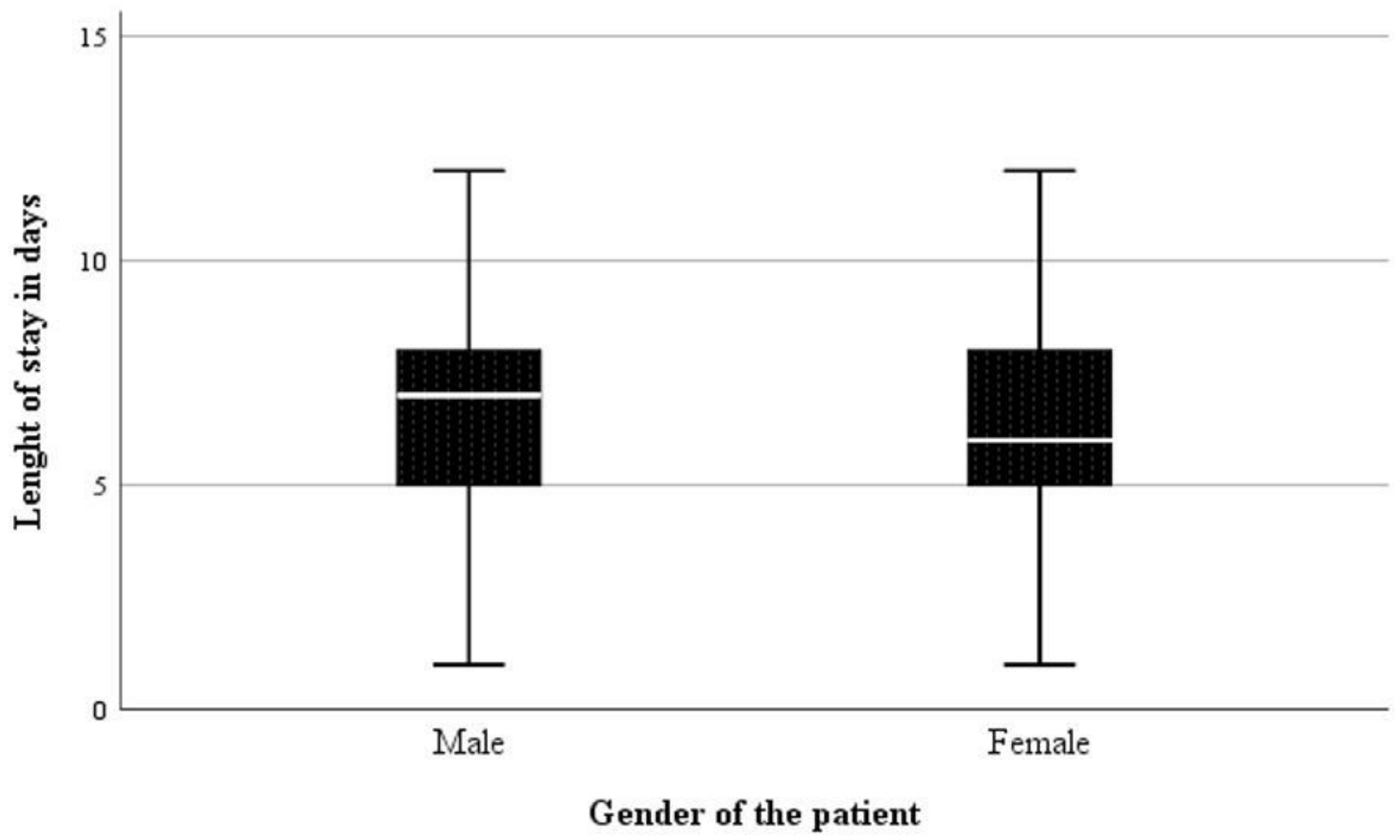

Figure 2

Simple boxplot of the length of stay in days by gender of the patient 


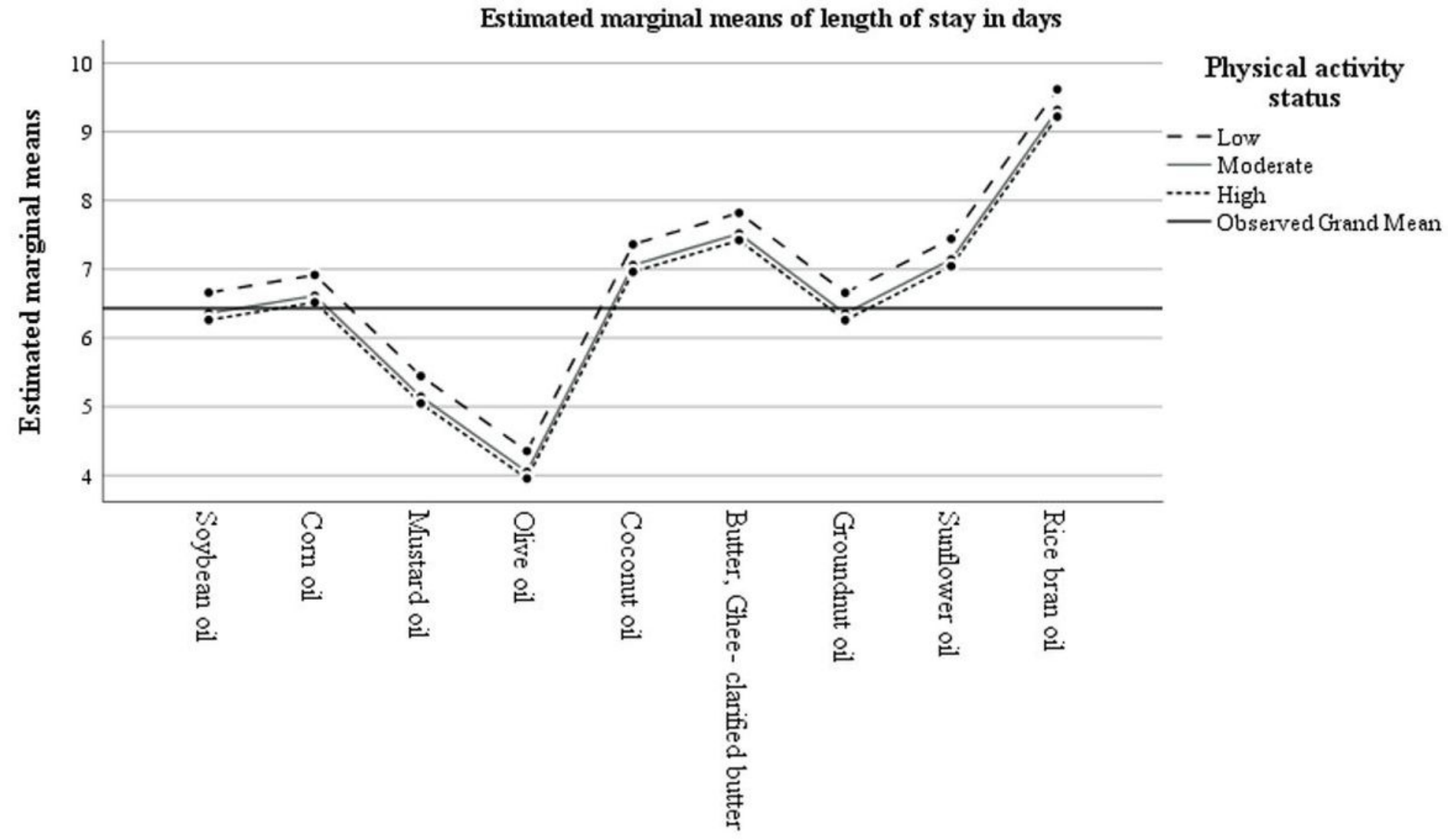

Type of cooking oil used by patients

\section{Figure 3}

Estimated marginal means of the length of stay in days with the type of cooking oil with physical activities 


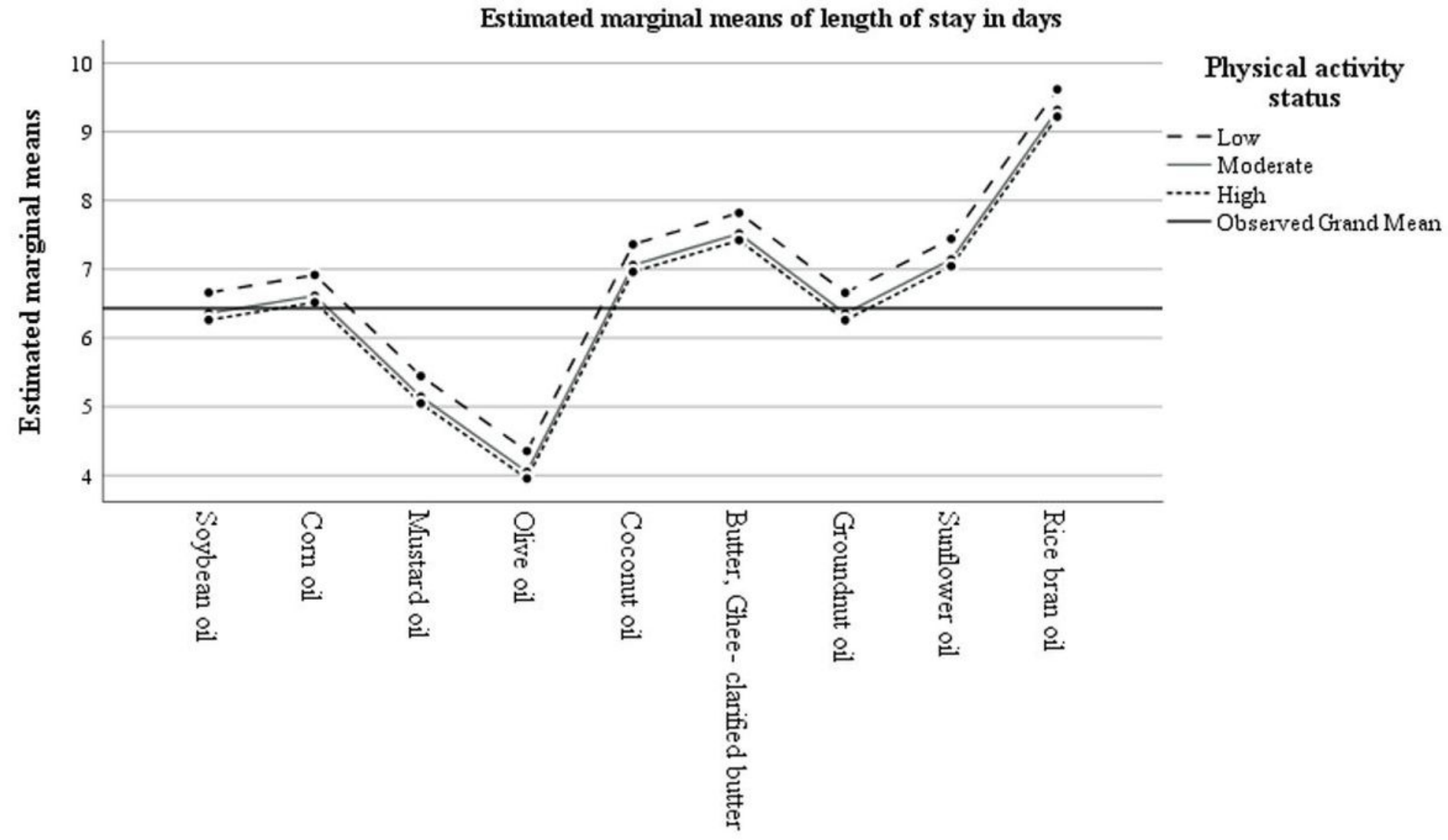

Type of cooking oil used by patients

\section{Figure 3}

Estimated marginal means of the length of stay in days with the type of cooking oil with physical activities 


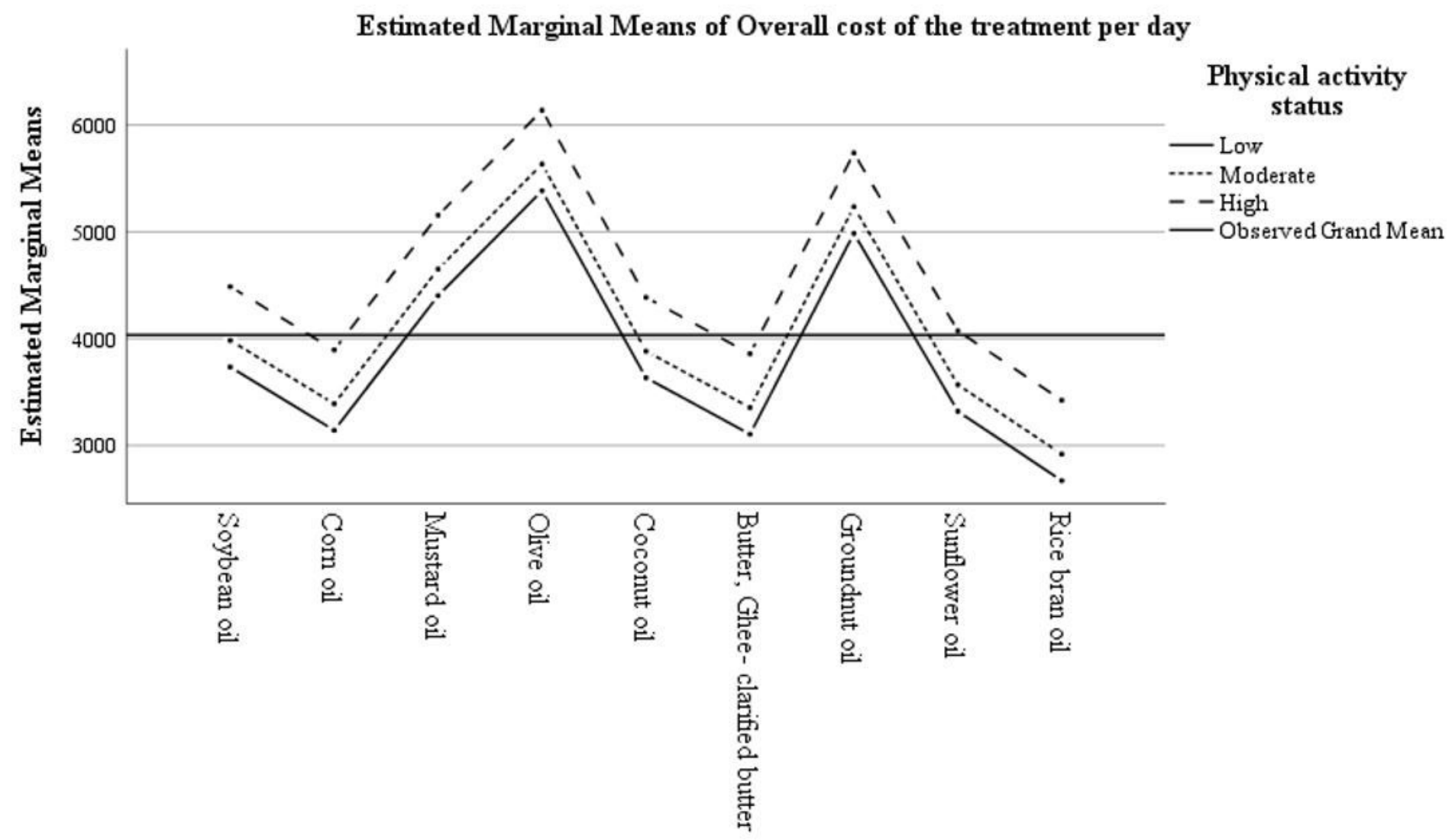

Type of cooking oil used by patients

\section{Figure 4}

Estimated marginal means of the overall cost of the treatment per day in INR with the type of cooking oil with physical activities 


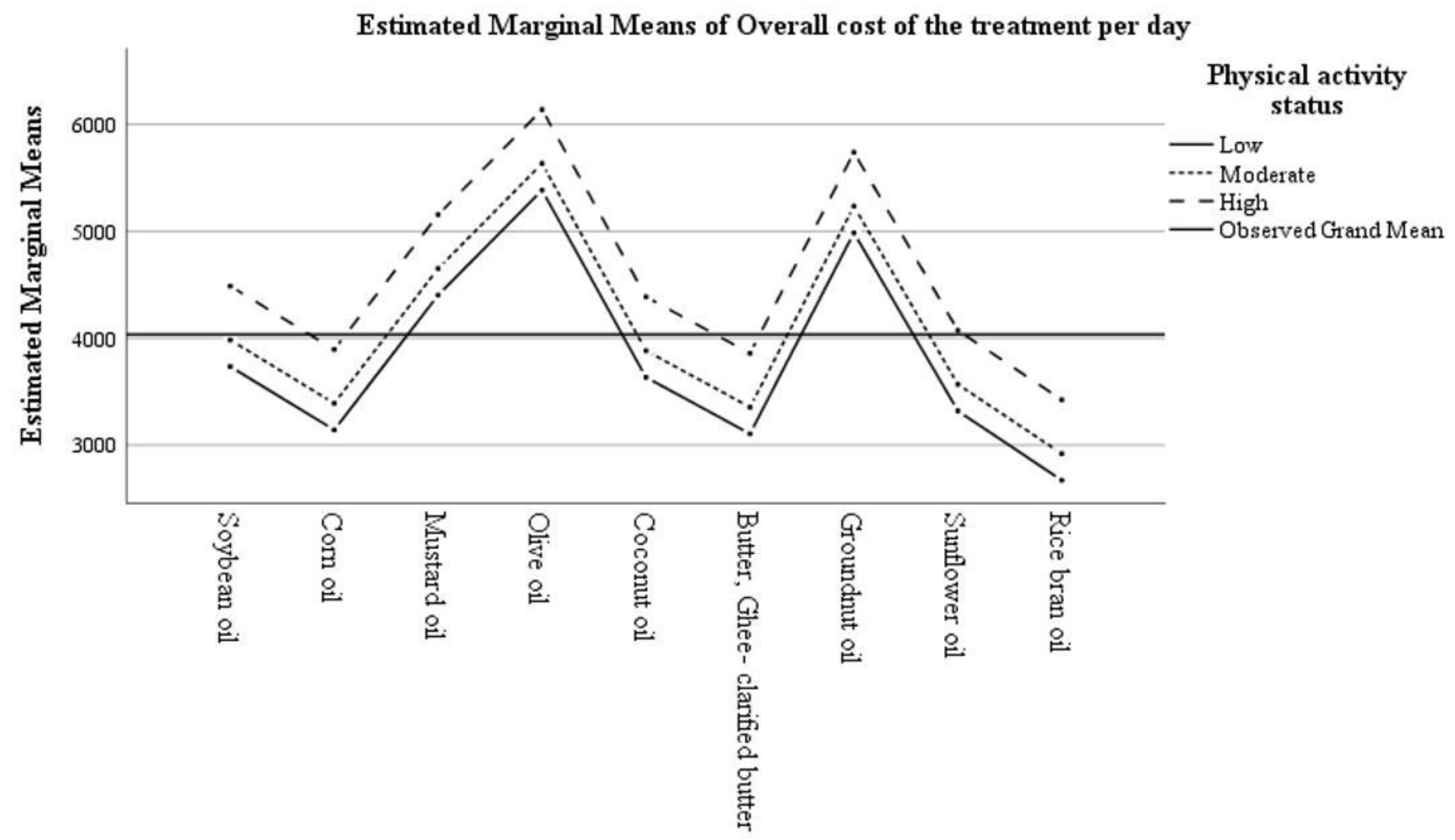

Type of cooking oil used by patients

\section{Figure 4}

Estimated marginal means of the overall cost of the treatment per day in INR with the type of cooking oil with physical activities 